\title{
Quantitative Analysis of the Value Investments of Listed Companies in China's Mining Industry
}

\author{
Tao Zhu ${ }^{1}$, John Walsh ${ }^{2}$, \& Fuangfa Ampornstira ${ }^{3}$ \\ ${ }^{1}$ Ph.D., Candidate, Management, School of Management, Shinawatra University, Thailand \\ ${ }^{2} \mathrm{Ph}$. D., International Business, School of Business and Management, RMIT, Vietnam \\ ${ }^{3} \mathrm{Ph}$. D., Management, School of Management, Shinawatra University, Thailand \\ Correspondence: John Walsh, Ph. D., International Business, School of Business and Management, RMIT, \\ Vietnam. E-mail: jcwalsh100@ hotmail.com
}

Received: July 7, 2020

doi:10.5539/ibr.v13n10p31
Accepted: August 28, $2020 \quad$ Online Published: September 11, 2020

URL: https://doi.org/10.5539/ibr.v13n10p31

\begin{abstract}
Value investment (VI) has been widely studied and applied to many fields of stock market analysis. It involves the identification of under-priced stocks for possible purchase and subsequent resale. In this paper, quantitative methods are employed to examine the extent and nature of VI in China's mining industry. The research aims to discover the relationships between return on investment (ROI) and the historic financial indices documented in financial statements, while also examining the extent of the influence of VI on ROI in the Chinese mining industry.
\end{abstract}

Keywords: China, mining industry, quantitative analysis, ROI, value investment

\section{Introduction}

\subsection{Status Quo of the Chinese Stock Market and Listed Companies in the Mining Industry}

The Chinese economy has grown at a fast pace since market opening and the reform policy was launched in 1979. By comparison, China's stock market has performed poorly compared with economic fundamentals because of serious distortions in prices. There is no clear statistical relationship between growth in the economy as a whole and the performance of the stock exchange. Compared to stock markets in, for example, the USA and Hong Kong, China's stock market has been experiencing long-run consolidation amid drastic fluctuations. Although stock market performance has been problematic over the past decade or so, it has been particularly anemic in China because of the contrast with robust GDP growth over the same period (e.g. Russolillo, 2020). Is it possible to identify the reasons for that poor performance in such a way that it provides lessons for future growth? To try to answer this question, one important sector of the Chinese stock market is selected, the mining sector, since the performance of this sector is directly related to fundamental national economic performance and some of the volatility of international transactions is removed.

According to the newest standards on the classification of industry in the Chinese stock market (as of $31^{\text {st }}$ December 2019) released by the China Securities Regulatory Commission, Chinese listed companies in mining industry comprised 78 entities (see Table 1 below).

Table 1. Basic Information on Chinese Listed Companies in Mining Industry

\begin{tabular}{ll|lll}
\hline Listing Periods & Number & ROI (2016-2018) & Number & \%age \\
\hline Less than 6 years & 10 & Positive & 18 & 26.5 \\
Over 6 years & 68 & Negative & 50 & 73.5 \\
Total & 78 & Total & 68 & 100.0 \\
\hline
\end{tabular}

Source: Adapted by Authors from Stock Market Information

In Table 1 above, the listing periods of the companies involved are divided between less than and more than six years, while the overall results of return on investment (ROI) from 2016-18 are also listed. As can be seen, these results were far below the presumed expectations of investors, especially given the intensive drive in building 
infrastructure and urban environments across China. From 2016-8, only 18 listed mining companies (26.5\%) showed a positive ROI, while 50 (73.5\%) showed negative ROI. These poor results might have been caused by problems in the stock market, poor financial management or both.

In calendar years 2016-2018, only 18 listed companies (accounting for 26.5\% of the total number) gained positive ROI which came from the increase in capital and net profit made by the listed companies, while 50 listed companies ( $73.5 \%$ of the total) in the mining industry failed to supply satisfactory rewards to their investors. The average ROI (2016-2018) indicated that the listed companies in the mining industry suffer from poor performance in the recent years which may be caused by trends in the stock market overall or its poor financial management.

\subsection{Research Objectives and Questions}

The objectives of this research project are as follows:

1. To ascertain the factors influencing ROI in the listed companies of the Chinese mining industry.

2. To examine the extent of the association between ROI and the factors that influence it.

3. To ascertain the causes of change of influencing factors and the relationship between them.

The research questions can be derived from the research objectives and are as below:

1. What factors influence ROI in the listed companies of the Chinese mining industry?

2. What is the nature and extent of the relationship between ROI and its influencing factors?

3. What are the factors influencing ROI themselves affected by and what are the interactions between them?

\subsection{Conceptual Framework}

The conceptual framework for this project is shown below.

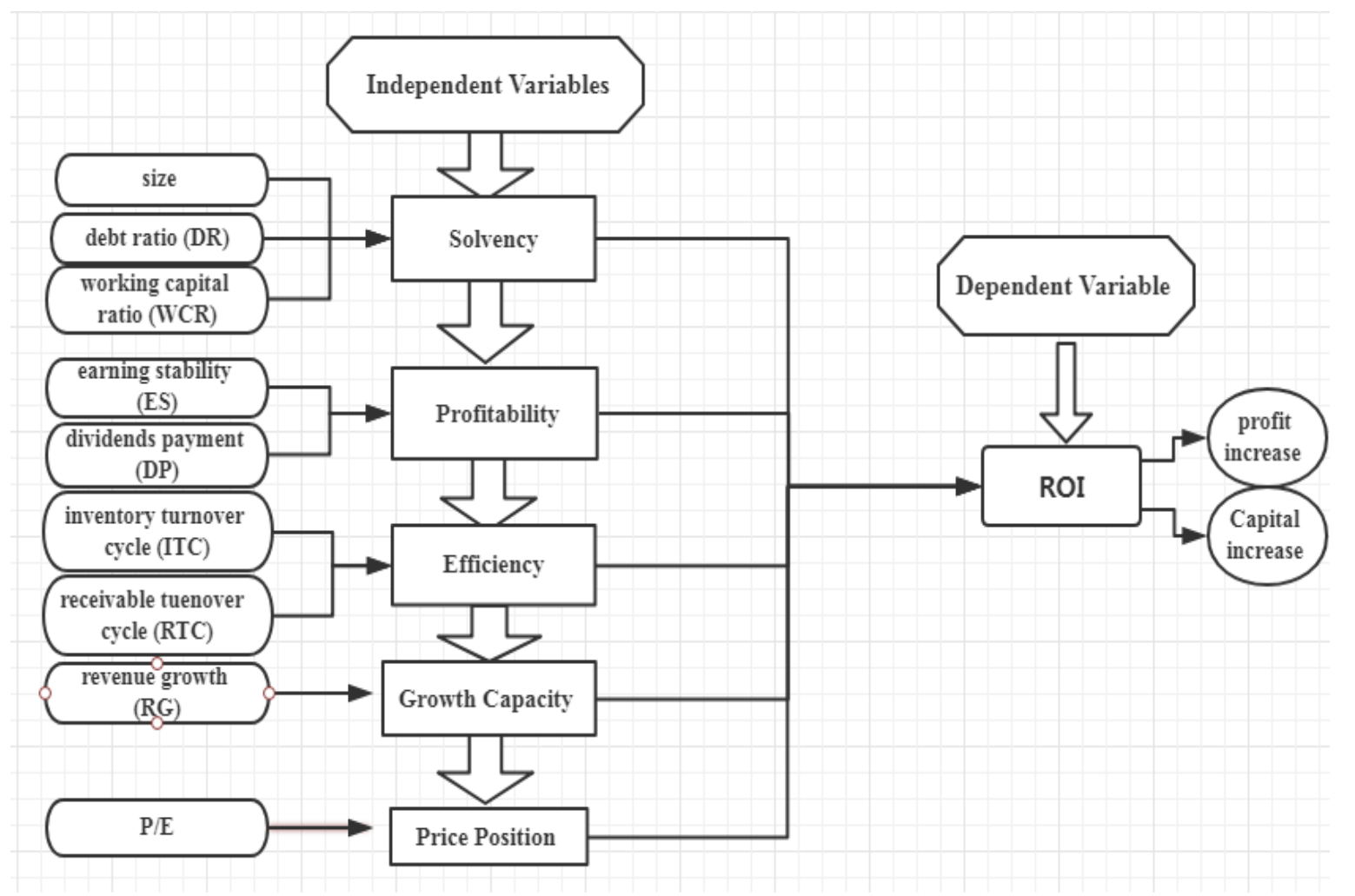

\subsection{Research Hypotheses}

Based on the research framework above, it is possible to state the research hypotheses of this project as:

H1: There is a relationship between ROI and solvency.

$\mathrm{H} 2$ : There is a relationship between ROI and profitability.

H3: There is a relationship between ROI and efficiency. 
H4: There is a relationship between ROI and growth capacity.

H5: There is a relationship between ROI and price position.

These hypotheses will be tested in null format with a 95\% level of confidence.

\section{Literature Review}

\subsection{Theory of Stock Price Prediction}

Modern Portfolio Theory (MPT) suggests that the expected return of the portfolio is calculated as a weighted sum of the individual asset's returns, and the portfolio's risk is a complex function of the variances of each asset and the correlation of each pair of assets. Based on the assumption of the relationship between risk and returns of portfolio, each combination of assets can be plotted on a graph which shows the most and least desirable portfolio with the expected return on the Y-axis, while the risk analysis appears on the $\mathrm{X}$-axis. It is possible to draw a sloping hyperbola to connect all of the most efficient portfolios and that curve is known as the efficiency frontier, beyond which investing in any portfolio is not desirable (Markowitz, 1952).

Capital Asset Pricing Model (CAPM) is based on the MPT. Sharpe (1964), Lintner (1965) and Mossin (1966) have extended the basic concepts of MPT and developed the theory of the CAPM, with the formula of Ra $=\mathrm{Rf}$ $+\beta(\mathrm{Rm}-\mathrm{Rf})$, where: $\mathrm{Rf}=$ the rate of return for a risk-free security, $\mathrm{Rm}=$ the broad market's expected rate of return, $\beta=$ the beta of the asset.

Arbitrage Pricing Theory (APT) is derived by questioning the strict and inflexible application of CAPM. Ross (1976) proposed APT as an alternative to CAPM. By relaxing strict conditions, the alternative model is still able to provide better estimates of the expected stock returns than the CAPM (Fama \& French, 1997). The formula is Expected return $=R(f)+b(1) \times R p(1)+b(2) \times R p(2)+\ldots+b(n) \times R p(n)$, where $R(f)=$ the risk-free interest rate, $\mathrm{b}=$ the sensitivity of the asset to the particular factor and $\mathrm{Rp}=$ the risk premium associated with the particular factor.

Based on APT, a financial asset's expected return can be represented as a linear formula of a range of macro-economic factors with a beta coefficient for each factor. The obtained rate of return can be used to discount the future payoffs to present the value of the asset.

The B-S model (Black \& Scholes, 1973; Merton, 1973) also based their work on the arbitrage theory to develop a formula for pricing options. The B-S model is an investing tool used to determine the fair price or theoretical value for a call or a put option based on six variables, which are time, strike price, underlying stock price, volatility, type of option, risk-free rate. This model is widely employed by option traders who purchase options below the formula's calculated value or sell it over the B-S calculated value.

The Fama-French Three -Factor Model (Fama \& French, 1993) extended the CAPM by adding size risk and value risk factors into the market risk. By including these two additional factors in the CAPM formula, the model suggests that value and small-cap stocks outperform markets on a regular basis and, also, it is essentially the outcome of an econometric regression of historic stock prices.

\subsection{Trend Theory}

Trend theory attempts to predict the movements of a stock price based on recently observed data. The trends of the stock market can be divided into three types: short-, intermediate- and long-term. Trend traders employ a variety of indicators to analyze the movements of stock prices to extract profits from the trend, e.g. moving averages (MA), momentum indicators, trend lines and chart patterns. MACD (Moving Averages Convergence/Divergence), for example, is a trading indicator used to uncover the variation in the strength, direction, momentum and duration of a trend in a stock's price (Appel, 2005:166). RSI (Relative Strength Index) is classified as a momentum oscillator that is intended to chart the current and historic strengths or weaknesses of a stock or market based on the closing prices of a recent trading period (Wilder, 1978). TSI intends to show both trend direction and overbought/oversold conditions by using moving averages of the underlying momentum of a financial instrument. DMI (Directional Movement Index) identifies in which direction the price of an asset is moving by comparing prior highs and lows and drawing two lines, one in a positive and the other in a negative direction (ibid.).

\subsection{Value Investing Theory}

Value investing theory was established by the father of Wall Street Benjamin Graham, who held that stocks should be traded for not more than their intrinsic values. Benjamin Graham came up with seven criteria for defensive investors who would like to assure the safety of the principal and earn properly: (1) adequate size of enterprise; (2) sufficiently strong financial conditions; (3) earnings stability; (4) dividend record; (5) moderate 
price/earnings ratio; (6) moderate ratio of price to asset and (7) earnings growth (Graham, 2003:348-9).

Further, Graham proposed five standards for value investing for enterprising investors as follows: (1) financial conditions: current asset at least 1.5 times current liabilities and debt not more than $110 \%$ of net current assets (for industry companies); (2) earnings stability: no deficit in the last five years as covered in the Stock Guide; (3) dividend record: some current dividends; (4) earnings growth and (5) price: less than $120 \%$ net tangible assets (ibid.).

In addition to the standards above, Graham proposed more specific criteria for the selection of stocks in three different industries including railways and public utilities as well as industry. In the Security Analysis written by Graham and Dodd (2009:105-6), it was shown that the results of investing in industry suggest that the nature of the industry is very different from railways and public utilities, in that it is more uncertain, changeable and the size of the listed corporation is the critical aspect that the investors should take into account while making investing decisions in such a case.

There have been other approaches to value investing have furthered and broadened the value investing theory by academic research and practice. Value Investing: From Graham to Buffett and Beyond written by Greenwald et al. (2004), for example, mainly deals with some specific variables including book value, reproduction costs, franchise, risk, diversification and default to improve the methods in eventuating the assets, earning power and corporate growth. Another follower, Piotroski (2000), examined whether a simple accounting-based fundamental analysis strategy, when applied to a broad portfolio of high book to market firms, can shift the distribution of returns earned by an investor. The paper showed that investing in high book-market companies could outperform low book-market ones by increasing by up to $75 \%$ annually or, at least, by $23 \%$ from 1976-1996. Huang Hui Ping and Huang Bo (2012) proposed that value investing still worked in the Chinese A-share market by testing 14,655 listed corporations (1998-2009) on the basis of their financial statements. Ke Yuan (2011) concluded that value investing methods, combined with amended modern portfolio theories, including MPT and CAPM, which exclude $\beta$ 's impact in calculating the formula, still performed well when applied to the SSE180 index. Gan and Zhang (2018) indicated that the value investing methods were still efficient in the Chinese A-share market by using a Multi-Factor Pricing Model based on value investing methods to test 475 listed corporations in that market (2007-2016). Meanwhile, other researchers focused on the analysis of the relevance of certain financial indices based on value investing principles by employing statistical methods to construct the theory. Lai and Chen (2013) examined the relevance of the stock price and other financial indices in a selected 619 listed corporations (2009-2011) by using Pearson testing and linear regression analysis.

In this research study, quantitative analysis will be employed to test the validity of the principle of value investment in China's mining industry, which is an issue that has seldom been investigated in this context. Consequently, this research would like to further extend value investment study into a more specific field in order to fill the gap in academic knowledge in China.

\section{Research Methodology}

\subsection{Definition of Population}

This research will define the population as 78 listed corporations in the mining industry as of $31^{\text {st }}$ December 2019, in the classification of the industry according to the China Securities Regulatory Commission.

\subsection{Methods of Data Analysis}

Both traditional analysis of financial statements and an inferential statistical method will be taken into account for analysis of the data. In this research, the researchers will make use of the traditional financial analysis of the financial figures, as below:

(1) ROI (2016-2018): (capital and profit increase/investment) A. positive; B. negative

(2) Size (2015): based on gross revenue in 2015. A. small ( $\leq 5$ billion); B. medium (5-15 billion); C. large (>15 billion)

(3) Debt Ratio (2015): A. $\leq 40 \%$; B. $40-70 \%$; C. $>70 \%$

(4) Working Capital Ratio (2015): A. $>1.5$ times; B. $\leq 1.5$ times

(5) Earnings Stability (2013-2015): positive for three consecutive years (A. Yes; B. No)

(6) Dividend Payments (2013-2015): some dividend for 3 years (A. Yes; B. No)

(7) Inventory Turnover Cycle (2013-2015): A. $\leq 30$ days; B. 31-90 days; C. > 90days

(8) Receivables Turnover Cycle (2013-2015): A. $\leq 90$ days; B. 90-180 days; C. >180days 
(9) Revenue Growth (2013-2015): growth for three consecutive years (A. Yes; B. No)

(10) $P / E$ (2013-2015): the value of $P$ is taken from the end of 2015 and the value of $E$ is the averaging of three years' earning per share. A. $\leq 15$ times; B. 15-30 times; C. $>30$ times; D. negative

As discussed above, inferential statistical methods could also help in examining the relationship between ROI and other proposed variables. By means of SPSS software, examination of the hypotheses proposed in 1.4 has been conducted.

\section{Findings}

In this research, 68 listed companies in the mining industry were selected for analysis. A further ten listed companies did not meet the criteria for the research time span and have been excluded.

\subsection{Descriptive Analysis of the Variables}

Table 2. Size of Companies; source: Original Research

\begin{tabular}{|l|l|l|}
\hline & Frequency & \%age \\
\hline Small & 35 & 51.5 \\
\hline Medium & 14 & 20.6 \\
\hline Large & 19 & 27.9 \\
\hline $\mathrm{N}$ & 68 & \\
\hline
\end{tabular}

Table 3. Debt Ratio (2015); source: Original Research

\begin{tabular}{|l|l|l|}
\hline & Frequency & \%age \\
\hline Less than 40\% & 22 & 32.4 \\
\hline $40-70 \%$ & 37 & 54.4 \\
\hline More than 70\% & 9 & 13.2 \\
\hline $\mathrm{N}$ & 68 & \\
\hline
\end{tabular}

Table 4. Working Capital Ratio (2015)

\begin{tabular}{|l|l|l|}
\hline & Frequency & \%age \\
\hline Less than 1.5 times & 22 & 32.4 \\
\hline More than 1.5 times & 46 & 67.6 \\
\hline $\mathrm{N}$ & 68 & \\
\hline
\end{tabular}

Table 2, 3 and 4 above indicate the variables that are used to create the solvency construct as an independent factor in the overall analysis. The results for debt ratio and working capital ratio indicate problems with liquidity for many of the companies involved. This problem suggests a risk of bankruptcy if it cannot be remedied.

The profitability construct as an independent factor was measured by a combination of earnings stability and dividends payment, as shown in Tables 5 and 6 below.

Table 5. Earning Stability (2013-5); source: Original Research

\begin{tabular}{|l|l|l|}
\hline & Frequency & \%age \\
\hline Yes & 44 & 64.7 \\
\hline No & 24 & 35.3 \\
\hline N & 68 & \\
\hline
\end{tabular}

Table 6. Dividends Payments (2013-5); source: Original Research

\begin{tabular}{|l|l|l|}
\hline & Frequency & \%age \\
\hline Yes & 58 & 85.3 \\
\hline No & 10 & 14.7 \\
\hline N & 68 & \\
\hline
\end{tabular}

These results for profitability indicate that most of the firms investigated are profitable according to these criteria. However, the results are not as positive as might be expected. The next results dictate the efficiency construct, which is composed of inventory turnover cycle and receivables turnover cycle, as seen below. 
Table 7. Inventory Turnover Cycle (2013-5); source: Original Research

\begin{tabular}{|l|l|l|}
\hline & Frequency & \%age \\
\hline Less than 30 days & 20 & 29.4 \\
\hline 30-90 days & 34 & 50.0 \\
\hline More than 90 days & 14 & 20.6 \\
\hline N & 68 & \\
\hline
\end{tabular}

Table 8. Receivables Turnover Cycle (2013-5); source: Original Research

\begin{tabular}{|l|l|l|}
\hline & Frequency & \%age \\
\hline Less than 90 days & 39 & 57.4 \\
\hline $90-180$ days & 18 & 26.5 \\
\hline More than 180 days & 11 & 16.2 \\
\hline N & 68 & \\
\hline
\end{tabular}

The results for both of these variables indicated some possible problems with efficiency, since the life cycles for both inventory and receivables are longer than would be optimal. This is perhaps an indication of poor management, although there may be other explanatory factors that are not immediately obvious.

The next independent factor is growth capacity, which is measured in this research study by revenue growth (2013-5) (see Table 9 below).

Table 9. Revenue Growth (2013-5); source: Original Research

\begin{tabular}{|l|l|l|}
\hline & Frequency & \%age \\
\hline Yes & 15 & 22.1 \\
\hline No & 53 & 77.9 \\
\hline N & 68 & \\
\hline
\end{tabular}

These results indicate a general lack of growth in the mining sector companies investigated here. This negative picture was reinforced by the results for price earnings per share, which are shown in Table 10 below.

Table 10. Price Earnings per Share (2013-5); source: Original Research

\begin{tabular}{|l|l|l|}
\hline & Frequency & \%age \\
\hline Less than 15 times & 8 & 11.8 \\
\hline 15-30 times & 12 & 17.6 \\
\hline More than 30 times & 30 & 47.1 \\
\hline Negative & 16 & 23.5 \\
\hline N & 68 & \\
\hline
\end{tabular}

These results suggest that as many as $65 \%$ of the listed companies explored were overpriced and a further $23.5 \%$ had negative earnings per share, which is indicative of a difficult business environment.

Having established the independent factors to be used in this analysis, it is now possible to test the research hypotheses.

\subsection{Hypothesis Testing}

Hypothesis testing investigated the possible interactions between the independent factors specified in Tables 2 to 10 above and the dependent factor (ROI), as well as interactions between the independent factors. These tests are conducted via bivariate correlations, as shown in Table 11 below.

Table 11. Hypothesis Testing; source: Original Research (* significantly correlated at the 0.05 level; ** significantly correlated at the 0.01 level $)(n=68)$

\begin{tabular}{|l|l|l|l|l|l|l|l|l|l|l|}
\hline & ROI & PE & ES & SIZE & RG & DR & WCR & ITC & RTC & DP \\
\hline ROI & - & $0.283^{*}$ & 0.234 & $-0.281^{*}$ & 0.083 & 0.029 & -0.130 & $0.305^{*}$ & 0.115 & 0.061 \\
\hline Size & $-0.281^{*}$ & $-0.275^{*}$ & $-0.263^{* *}$ & - & -0.022 & $0.289^{*}$ & $0.323^{* *}$ & $-0.327^{* *}$ & $-0.286^{*}$ & -0.128 \\
\hline ITC & $0.305^{*}$ & 0.090 & 0.137 & $-0.327^{* *}$ & -0.067 & -0.102 & -0.132 & - & -0.069 & 0.171 \\
\hline PE & $0.283^{* *}$ & - & $0.608^{* *}$ & $-0.275^{*}$ & 0.052 & $0.313^{* *}$ & -0.064 & 0.090 & 0.171 & 0.214 \\
\hline
\end{tabular}


It is evident from Table 11 that three statistically significant distributions have been obtained here, which suggests that there are relationships between ROI and PE, Size as well as ITC. Meanwhile, ROI is weakly negatively correlated with Size and slightly positively correlated with PE and ITC, which is consistent with the work of Benjamin (1934). However, the results show that there were no associations between ROI and ES, RG, DR, WCR, RTC or DP and this contradicts the work by Benjamin (2003). These results may indicate that traditional value investing theory should be further studied in heterogeneous conditions so as to be applied by investors more flexibly. Besides, further analysis of Size, PE and ITC is necessary for this research.

It seems that the most powerful explanatory factor is size and, since the coefficients are often negative in this case, it suggests that the larger companies experience more problems with management. This is a logical conclusion based on the organizational history of China.

In terms of the hypotheses:

H1: There is a relationship between ROI and solvency.

$\mathrm{H} 2$ : There is a relationship between ROI and profitability.

H3: There is a relationship between ROI and efficiency.

H4: There is a relationship between ROI and growth capacity.

H5: There is a relationship between ROI and price position.

\subsection{Discussion}

In this research study, quantitative analysis has been employed to test the validity of the principle of value investment in China's mining industry, because this is an area that has lacked research in China until now. Most research has been conducted at the stock market overall level rather than the sectoral level. Consequently, this research would like to further investigate the value investment approach in more specific fields in order to fill the academic gap in China.

The results indicate that there are relationships between ROI and Size, P/E as well as ITC. However, there is no evidence of an association between ROI and DR, WCR, ES, DP or RG, as well as RTC, which contradicts previous studies of value investment such as Benjamin (2003).

\section{Conclusion}

In this research, five proposed influential factors of ROI including solvency, profitability, efficiency, growth capacity as well as price position have been tested and analyzed. In the Chinese mining industry, the ROI of $73.5 \%$ listed companies were negative during 2016-2018, which may indicate medium- or long-term solvency issues. Further, relatively low operational efficiency problems still existed in mining listed companies which may cause further liquidity issues. From 2013 to 2015, only 22.1\% listed companies' gross revenue in the mining industry had grown on an annual basis, which implied that the whole mining industry lacks momentum for sustainable development. The results indicated that approximately $65 \%$ listed companies in the research were overpriced and 16 listed companies suffered a tough business period as indicated by negative PE. A quantitative analysis conducted to test the research hypotheses finds that ROI has relationships with Size and ITC as well as PE, which are influenced by other financial indices discussed above.

\section{References}

Appel, G. (2005). Technical analysis: Power tools for active investors. Upper Saddle River, N.J.: Financial Times Prentice Hall: 166.

Black, F., \& Scholes, M. (1973). The pricing of options and corporate liabilities. Journal of Political Economy, 81(3), 637-654. https://doi.org/10.1086/260062

Fama, E. F., \& French, K. R. (1993). Common risk factors in the returns on stocks and bonds. Journal of Financial Economics, 33(3), 3-56. https://doi.org/10.1016/0304-405X(93)90023-5

Fama, E. F., \& French, K. R. (1997). Industry costs of equity. Journal of Financial Economics, 43, 153-193. https://doi.org/10.1016/S0304-405X(96)00896-3

Gan, W. M., \& Zhang, D. X. (2018). An empirical study on multi-factor pricing model in Chinese capital market based on value investment. Economic Survey, 136-140.

Graham, B. (2003). Intelligent investor. Revised edition. New York, N.Y.: Harper Collins Publisher.

Graham, B., \& Dodd, D. L. (2009). Security analysis (6th ed.). New York, N.Y.: McGraw Hill. 
Greenwald, B. C. N., Kahn, J., Sonkin, P. D., \& Van Biema, M. (2004). Value investing: From Graham to Buffett and beyond. Hoboken N.J.: Wiley.

Huang, H. P., \& Peng, B. (2012). Empirical research of value investing-based on the financial angel. Economic Management, 129-138.

Lai, X. C., \& Chen, F. (2013). Relevant research and regression analysis of value investing in security market based. The Theory and Practice of Finance and Economics, 26-29.

Lintner, J. (1965). The valuation of risk assets and the selection of risky investments in stock portfolios and capital budgets. Review of Economics and Statistics, 73, 13-37. https://doi.org/10.2307/1924119

Markowitz, H. M. (1952). Portfolio selection. The Journal of Finance, 7(1), 77-91. https://doi.org/10.1111/j.1540-6261.1952.tb01525.x

Merton, R. (1973). Theory of rational option pricing. Bell Journal of Economics and Management Science, 4(1), 141-183. https://doi.org/10.2307/3003143

Mossin, J. (1966). Equilibrium in a capital asset market. Econometrica, 34(4), 768-83. https://doi.org/10.2307/1910098

Piotroski, J. D. (2000). Value investing: The use of historical financial statement information to separate winners from losers. Journal of Accounting Research, 38, 1-41. https://doi.org/10.2307/2672906

Ross, S. A. (1976). The arbitrage theory of capital asset pricing. Journal of Economic Theory, 13, 341-360. https://doi.org/10.1016/0022-0531(76)90046-6

Russolillo, S. (2020). It was a lost decade for China's stock market, but investors bet on better times ahead. Wall Street Journal (January $\left.4^{\text {th }}\right)$. Retrieved from https://www.wsj.com/articles/it-was-a-lost-decade-for-chinas-stock-market-but-investors-bet-on-better-time s-ahead-11578133803

Sharpe, W. F. (1964). Capital asset prices: A theory of market equilibrium under conditions of risk. Journal of Finance, 19(3), 425-42. https://doi.org/10.1111/j.1540-6261.1964.tb02865.x

Wilder, J. (1978). New Concepts in Technical Trading Systems. Bloomington, IN: Trend Research.

Yuan, K. (2011). On optimal securities investment portfolio based on value investment theory. Journal of Fujian Institute of Financial Administrators, 11-17.

\section{Copyrights}

Copyright for this article is retained by the author(s), with first publication rights granted to the journal.

This is an open-access article distributed under the terms and conditions of the Creative Commons Attribution license (http://creativecommons.org/licenses/by/4.0/). 